\title{
Research regarding the action of the aerodynamic forces on a classical passenger train
}

\author{
Sorin Arsene* \\ Polytechnic University of Bucharest, Department of Railway Rolling Stock, Sector 6, Splaiul \\ Independenței, No. 313, Romania
}

\begin{abstract}
Technological development of the past decades has made it possible in the case of railway vehicles to continually improve dynamic and traction performance. This has determined, in the case of the conventional system (the railway vehicle on rails) a steady increase in travel speeds, reaching the record value $578 \mathrm{~km} / \mathrm{h}$. The current trend, in the case of the conventional classical trains composed from the locomotives and wagons are the maximum travel speeds to be at values of 200 $250 \mathrm{~km} / \mathrm{h}$. In the case of Electric multiple unit (EMU), the maximum speeds allowed in the current traffic are between $300-450 \mathrm{~km} / \mathrm{h}$. These increases in travel speeds would not have been possible without first studying in more detail the aerodynamic phenomena that act on the vehicles during their travel. This paper intends to analyses how the aerodynamic forces acts in the case of a classic passenger train formed up of a motor vehicles (locomotive) and three towed vehicles. For the determination of aerodynamic force values, an air flow simulation program will be used in case the train moves under normal atmospheric conditions.
\end{abstract}

\section{Introduction}

During the movement of a train, on the railway vehicles that make up, are a few forces that allow its movement. The arrangement of these forces is done as follows: in the sense of the movement of the train, is the traction force $\left(F_{0}(v)\right)$ developed by the power equipment placed on the motor vehicles, and in the opposite direction to the train movement are the sum of the resistance forces $\left(\sum R_{t}(v)\right)$, which opposes the displacement and the braking force $\left(F_{f}(v)\right)$ used to reduce the speed or to stop the train. At any time of the train movement, the values corresponding to these forces must be lower or at a limit equal to the limit of the adhesion force $\left(F_{a}(v)\right)$ of the track wheel contact. Under these conditions, the equilibrium equation for the forces acting on the vehicle in the longitudinal direction (the direction of travel of the train) can also be written in mathematical form according to [1-6] as follows:

$$
F_{0}(v)-\sum R_{t}(v)-F_{f}(v) \leq F_{a}(v)
$$

\footnotetext{
${ }^{*}$ Corresponding author: sorinarsene@gmail.com
} 
The values of the amount of resisting forces opposing movement, in situation where the vehicle would be moving in flat and alignment conditions (straight line without level deviations in vertical and transverse direction), are dependent on a series of frictions [1-6], such as: those in the axle bearings, rolling and / or slip between the wheel and the tread, with the air, of the current collector (patina, pantograph) and the contact line, etc.

To establish a mathematical relationship that can be used to calculate the values of the sum of resistant forces, it must consider many parameters that come during the movement. A solution to this problem is given using empirical computational formulas obtained experimentally.

In the literature [1-7] the first to establish an empirical mathematical relationship by which the value of the amount of forward-resistant forces was determined in the case of a railway vehicle was W.J. Davis. At present, its formula is generalized as a second-degree polynomial function (2).

$$
\sum R_{t-v}(v)=A+B \cdot v+C \cdot v^{2}
$$

where: $\sum R_{t-v}(v)$ - the sum of the total rolling resistance of a railway vehicle; $\mathrm{A}$ - mechanical rolling resistance $[\mathrm{N}]$; B - coefficient of non-aerodynamic drag resistance $[\mathrm{N} /(\mathrm{km} / \mathrm{h})] ; \mathrm{C}$ - drag coefficient determined by aerodynamic phenomena $\left[\mathrm{N} /(\mathrm{km} / \mathrm{h})^{2}\right] ; \mathrm{v}$ - vehicle speed $[\mathrm{km} / \mathrm{h}]$.

\section{Case study}

At present, in the Romanian rail passenger transport, most trains are of the classic type, consisting of a motor vehicle (locomotive) and a certain number of towed vehicles (wagons).

In the fleet of vehicles in operation at the national railway transport company in Romania (SNTFC "C.F.R. Călători" -S.A.), an important share of trains formed is with the single-deck wagons. For the analysis in this article we considered such a train made up of an electric locomotive of the type LE 060 EA of $5100 \mathrm{~kW}$ and a three single-deck wagons.

Considering the type of vehicles involved in the composition of trains in the literature [1-8], a series of values of Davis coefficients are specified, as shown in Table 1.

Table 1. Values of drag coefficients.

\begin{tabular}{|c|c|c|c|}
\hline Vehicle type & $\mathbf{A}[\mathbf{N}]$ & $\mathbf{B}[\mathbf{N} /(\mathbf{k m} / \mathbf{h})]$ & $\mathbf{C}\left[\mathbf{N} /(\mathbf{k m} / \mathbf{h})^{\mathbf{2}}\right]$ \\
\hline LE 060 EA of 5100 kW & 1700,1 & 11,8 & 0,4 \\
\hline Single-deck wagon & 82,5 & 0 & 0,0125 \\
\hline
\end{tabular}

Based on these coefficients, a rapid analysis can be made of the distribution pattern of the movement resistance components, in the case of the proposed train for analysis, according to Davis's relationship.

By way of example, in Figure 1 it is presented the variation of the train movement resistances $\left(R_{t}\right)$ considering the type of vehicles that make up the train, the locomotive $\left(\mathrm{R}_{\mathrm{L}}\right)$ and the wagons $(\mathrm{Rv})$, respectively. In Figure 2 it is shown components decomposition of the resistance force to the movement in according to the Davis formula, as follows: $\mathrm{R}_{\mathrm{t}} \mathrm{A}$ is the component of the rolling resistance, $\mathrm{R}_{\mathrm{t}_{-} \mathrm{B}}$ is the component of the resistance given by the non-aerodynamic forces and the $\mathrm{R}_{\mathrm{t}_{\mathrm{C}} \mathrm{C}}$ component given by the aerodynamic forces. In Figure 3 is a percentage report of the components shown in Figure 2 at the total train resistance value.

About the determination of parameter $\mathrm{C}$ (regarding aerodynamic resistances) in the generalized relation of Davis, in the literature [7-13] this is explained considering the forces generated by the air flow in the Cartesian coordinate system, as follows:

$$
C_{i}=2 \cdot F_{i} /\left(S \cdot \rho \cdot v^{2}\right)
$$




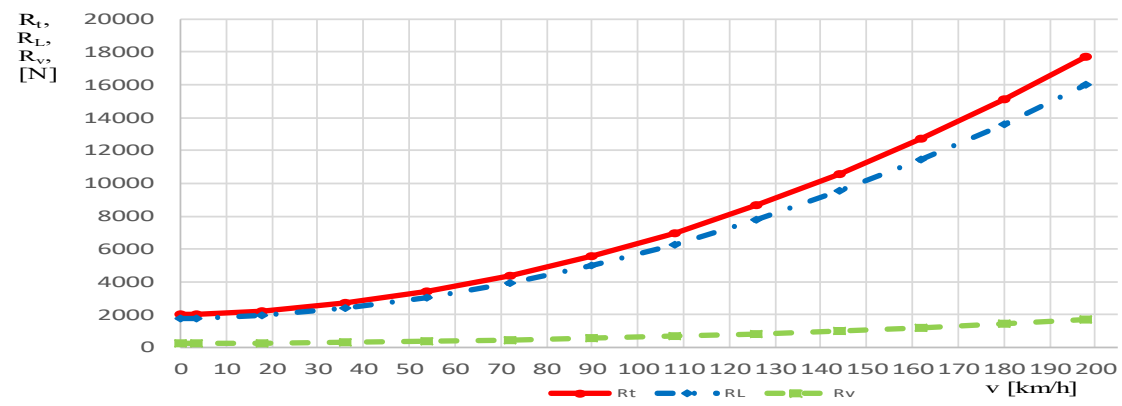

Fig. 1. The variation of the train strength tested, considering the type of vehicles it carries, according to the travel speed.

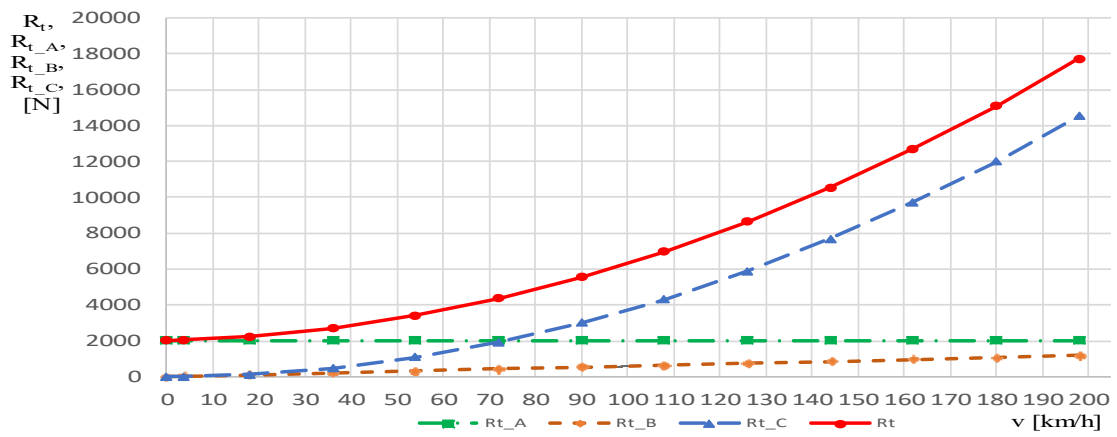

Fig. 2. The variance of the train's resistance, considering Davis's components, in terms of travel speed.

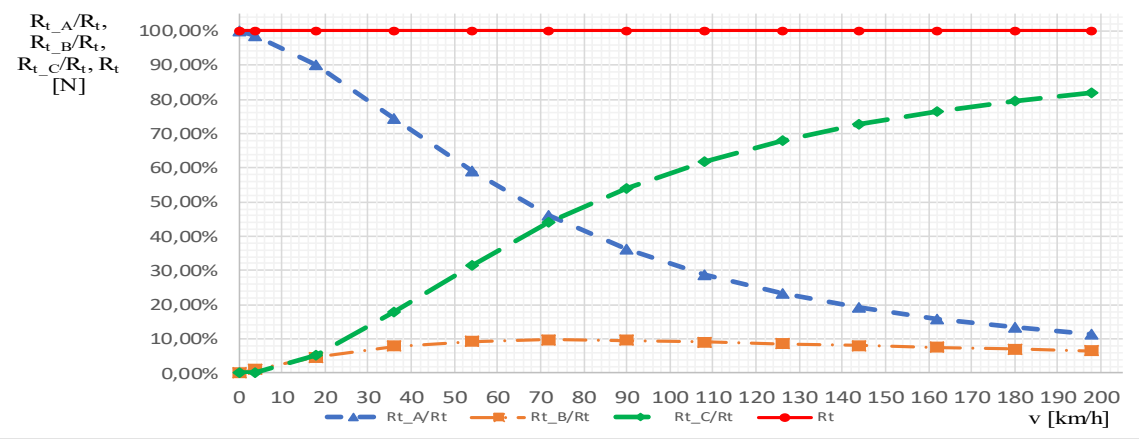

Fig. 3. Variation in percentage reporting of Davis's resistance components according to the travel speed.

Where: $\mathrm{i}$ - represents the axes of the Cartesian coordinate system Ox, Oy, Oz; S - cross section of the vehicle $\left(\mathrm{m}^{2}\right) ; \rho$ - air density in which the vehicle is traveling $\left(\mathrm{kg} / \mathrm{m}^{3}\right)$;

Aerodynamic forces can be determined both experimentally by using scale models in aerodynamic tunnels or using airflow simulation programs.

\section{Simulation of airflow}

In the airflow simulation process, we first started from geometric modeling in 3D format of a model at scale of the constructive forms of the two types of vehicles that make up the 
train. After which we assembled it according to the specified train (a motor vehicle and three towed vehicles) (Figure 4).

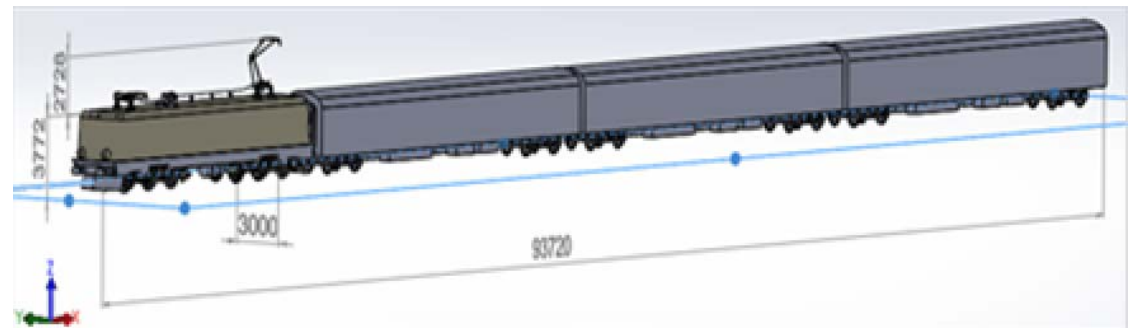

Fig. 4. 3D geometric model of the specified train (values in $\mathrm{mm}$ ).

The airflow simulation is performed for twelve-point values of the train speed in the range of $0 \mathrm{~km} / \mathrm{h}$ to $200 \mathrm{~km} / \mathrm{h}$. For these point values, it was considered that the train is moving under normal atmospheric conditions (pressure $101325 \mathrm{~Pa}$ and temperature 293.2 $\mathrm{K}$ ) and that the speed is maintained constant at: $1 \mathrm{~m} / \mathrm{s}, 5 \mathrm{~m} / \mathrm{s}, 15 \mathrm{~m} / \mathrm{s}, 20 \mathrm{~m} / \mathrm{s}, 25 \mathrm{~m} / \mathrm{s}, 30 \mathrm{~m} / \mathrm{s}$, $35 \mathrm{~m} / \mathrm{s}, 40 \mathrm{~m} / \mathrm{s}, 45 \mathrm{~m} / \mathrm{s}, 50 \mathrm{~m} / \mathrm{s}, 55 \mathrm{~m} / \mathrm{s}$.

We have then delimited an air flow volume (Figure 5), as follows:

- In the vertical direction: a plane located at the level of the running surface of rail and a second plane situated at $15 \mathrm{~m}$ from the first.

- In the transverse direction two symmetrical planes at $10 \mathrm{~m}$ from the longitudinal plane of the vehicle are considered.

- In the longitudinal direction: we started the transverse plane of the locomotive from which we considered a plane located $100 \mathrm{~m}$ from it (for the rear of the train) and a second plane at $20 \mathrm{~m}$ (for the front of the train).

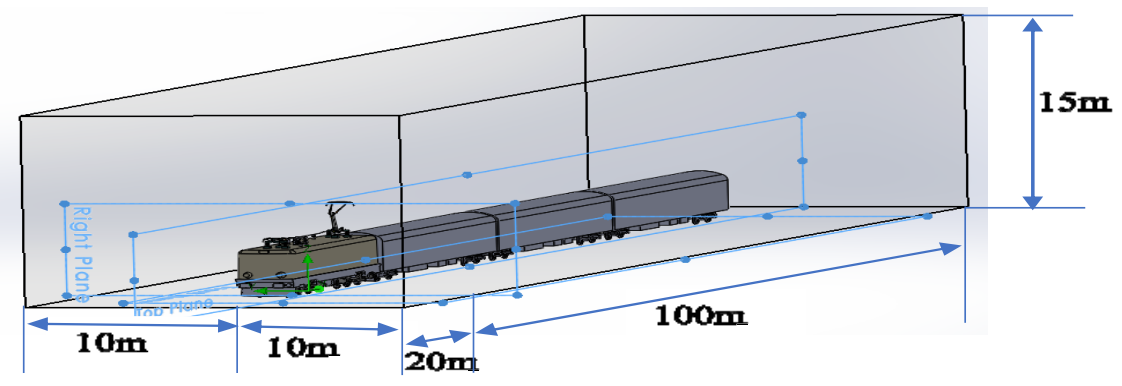

Fig. 5. Volume of air delimited for flow.

Figure 6 shows the distribution of dynamic air pressure in the longitudinal section of the train, resulting from simulations performed for a flow rate of $55 \mathrm{~m} / \mathrm{s}$. Still at the same air velocity value in Figure 7 shows the pressure distribution exerted on the train surface. 


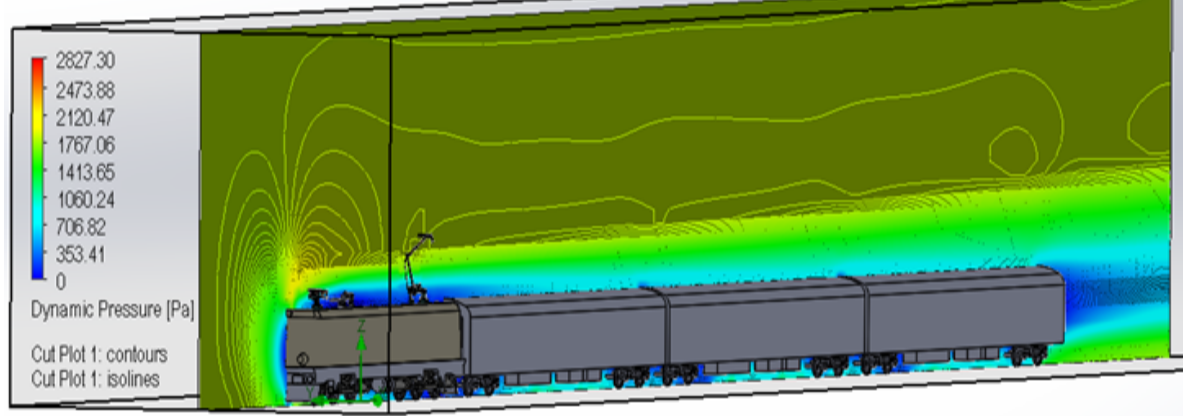

Fig. 6. Distribution of the dynamic pressure air to speed of $55 \mathrm{~m} / \mathrm{s}$.

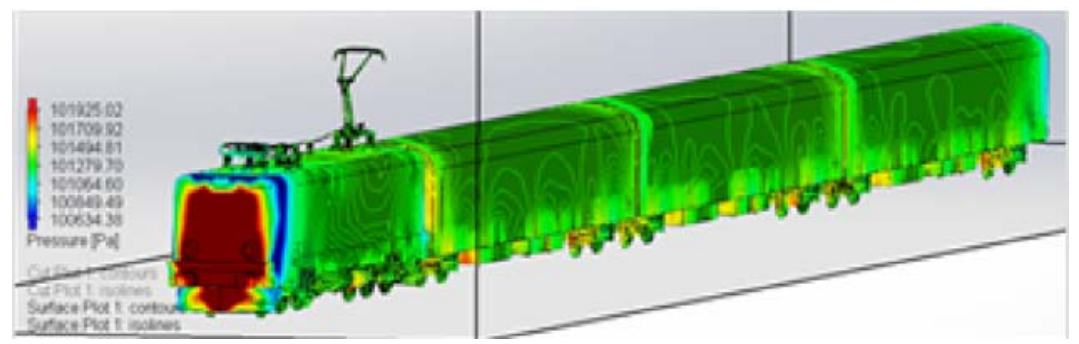

Fig. 7. The pressure exerted on the train at a speed of $55 \mathrm{~m} / \mathrm{s}$.

In Figure 8 shows the evolution during the simulation of the aerodynamic force for the twelve speed values analyzed on the flight over the train.

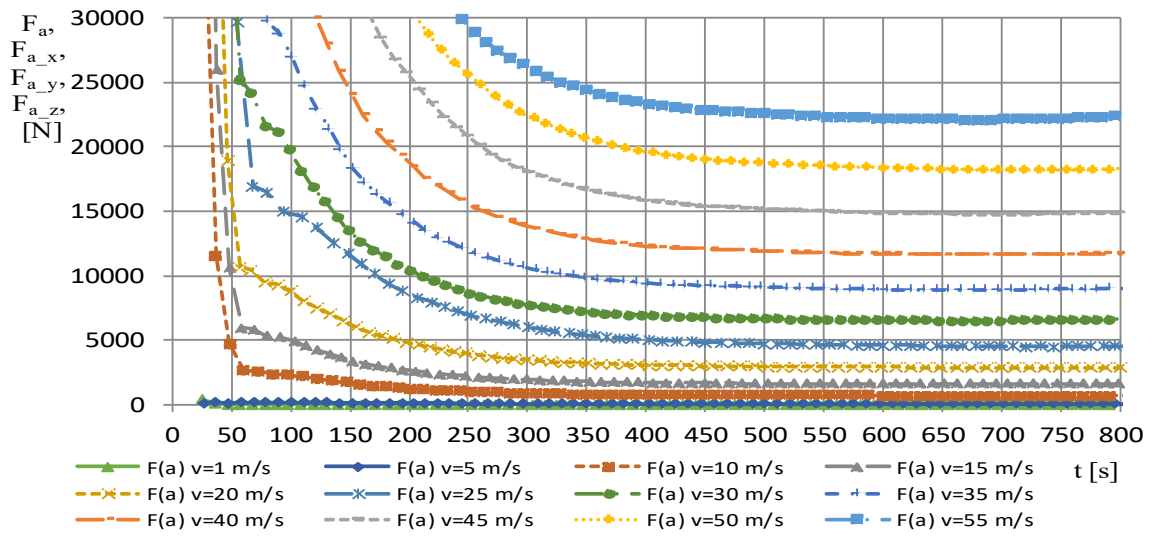

Fig. 8. Variation of aerodynamic forces during flow.

The stabilized values resulting from the simulations performed for the aerodynamic force train are shown in Table 2 and Table 3.

Table 2. Stabilized values of aerodynamic forces resulting from simulation to low speed.

\begin{tabular}{|c|c|c|c|c|c|c|c|}
\hline $\mathbf{V}$ & {$[\mathbf{m} / \mathbf{s}]$} & $\mathbf{1}$ & $\mathbf{5}$ & $\mathbf{1 0}$ & $\mathbf{1 5}$ & $\mathbf{2 0}$ & $\mathbf{2 5}$ \\
\hline $\mathbf{F}_{\mathbf{a}}$ & {$[\mathbf{N}]$} & 7,38 & 185,62 & 745,32 & 1678,35 & 2989,29 & 4678,31 \\
\hline $\mathbf{F}_{\mathbf{a} \_\mathbf{x}}$ & {$[\mathbf{N}]$} & 6,38 & 161,06 & 646,77 & 1458,67 & 2599,83 & 4063,48 \\
\hline $\mathbf{F}_{\mathbf{a} \mathbf{y}}$ & {$[\mathbf{N}]$} & $-0,08$ & $-3,07$ & $-11,44$ & $-28,12$ & $-48,33$ & $-72,08$ \\
\hline $\mathbf{F}_{\mathbf{a} \_} \mathbf{z}$ & {$[\mathbf{N}]$} & 3,71 & 92,22 & 370,22 & 829,67 & 1474,57 & 2317,21 \\
\hline
\end{tabular}


Table 3. Stabilized values of aerodynamic forces resulting from simulation to height speed.

\begin{tabular}{|c|c|c|c|c|c|c|c|}
\hline $\mathbf{V}$ & {$[\mathbf{m} / \mathbf{s}]$} & $\mathbf{3 0}$ & 35 & 40 & 45 & 50 & 55 \\
\hline $\mathbf{F}_{\mathbf{a}}$ & {$[\mathbf{N}]$} & 6732,37 & 9180,33 & 11987,82 & 15181,78 & 18780,24 & 22721,63 \\
\hline $\mathbf{F}_{\mathbf{a} \_\mathbf{x}}$ & {$[\mathbf{N}]$} & 5852,28 & 7975,60 & 10424,03 & 13202,68 & 16329,84 & 19752,69 \\
\hline $\mathbf{F}_{\mathbf{a} \mathbf{y}}$ & {$[\mathbf{N}]$} & $-115,23$ & $-154,94$ & $-220,10$ & $-252,03$ & $-314,11$ & $-401,12$ \\
\hline $\mathbf{F}_{\mathbf{a} \_\mathbf{z}}$ & {$[\mathbf{N}]$} & 3326,01 & 4543,60 & 5915,99 & 7490,82 & 9270,12 & 11222,43 \\
\hline
\end{tabular}

\section{Conclusions}

As can be seen, with increasing the speed of the train movement increases and the resistance to its advancement. The largest share of the values of this force has the component determined by the motor vehicle (locomotive). Using the analysis model resulting from Davis's relationship, it is found that at higher speeds the share of aerodynamic forces becomes significant, reaching $82 \%$ of the total value of the resistances to advancement. The aerodynamic forces resulting from air flow simulation, have the highest values distributed in the Cartesian coordinate system in the longitudinal direction, (which corresponds to the aerodynamic drag resistance), but also vertically. The vertical components are the result of a space of $0.86 \mathrm{~m}$ between the tread and the chassis of the vehicles. High values of the vertical aerodynamics force can lead to derailment or even roll-over of vehicles of the train composition. The reduction of vertical forces can be achieved using skirts (hulls, careen) on towed vehicles to mask the suspended chassis equipment. By simulating air flow, it was found that aerodynamic forces are higher by a percentage ranging from $34 \%$ to $36 \%$, as compared to the analysis of Davis' relationship. This percentage deviation can be improved by using a finer meshing of the volume elements.

This work was supported by a grant of the Romanian National Authority for Scientific Research and Innovation, CNCS-UEFISCDI, project number PN-III-P2-2.1-PTE-2016 -0008, within PNCDI III

\section{References}

1. A. Steimel, Munich: Elmar Krammer, (2008)

2. M. Allenbach, P. Chapas, M. Comte, R. Kaller, 1 2e édition, (2008)

3. D. A. Nicola, D. C. Cismaru, 1, Craiova, SITECH, (2011)

4. S. Arsene, I. Sebesan, Incas Bulletin, 6, 3 (2014)

5. S. Arsene, I. Sebesan, G. Popa, V. Stefan, U.P.B. Sci. Bull. D, 77, 4 (2015)

6. I. Sebesan, M. A. Spiroiu, S. Arsene, G. Popa, G. Dinu, 52, 4 (2015)

7. I. Sebesan, S. Arsene, G. Popa, The Influence of Air Currents on People and Facilities Near Railway, Procedia - Social and Behavioral Sciences, 186 (2015)

8. San-San Ding, Qiang Li, Ai-Qin Tian, Jian Du, Jia-Li Liu, Acta Mech. Sin. 32, 2 (2016)

9. S. Arsene, I. Sebesan, A. Certan, G. Popa, Procedia - Social and Behavioral Sciences, 186 (2015)

10. S. Arsene, I. Sebesan, G. Popa, Procedia - Social and Behavioral Sciences, 186 (2015)

11. S. Arsene, I. Sebesan, Analyze of aerodynamic forces acting on the Siemens Desiro railcar, Incas Bull., 8, 2 (2016)

12. S. Arsene, I. Sebesan, , Incas Bull., 8, 1, (2016)

13. I. Sebesan, S. Arsene, C. Stoica, U.P.B. Sci. Bull., D 75, 4 (2013) 